\title{
Binning effects on in-situ raindrop size distribution measurements
}

\section{R. Checa-Garcia ${ }^{1}$, A. Tokay ${ }^{2,3}$, and F. J. Tapiador ${ }^{4}$}

${ }^{1}$ Institute for Meteorology and Climate Research (IMK), Karlsruhe Institute of Technology (KIT), Karlsruhe, Germany

${ }^{2}$ Joint Center for Earth Systems Technology, University of Maryland Baltimore County, Baltimore, USA

${ }^{3}$ NASA Space Flight Center, Greenbelt, Maryland, USA

${ }^{4}$ Faculty of Environmental Sciences and Biochemistry. University of Castilla-La Mancha,

Toledo, Spain

Received: 14 December 2013 - Accepted: 10 February 2014 - Published: 7 March 2014 Correspondence to: R. Checa-Garcia (ramiro.garcia@kit.edu)

Published by Copernicus Publications on behalf of the European Geosciences Union.
Binning effects on in-situ raindrop size distribution measurements

R. Checa-Garcia et al.

Title Page

Abstract Introduction

Conclusions

References

Tables

Figures

14

4

Back

Close

Full Screen / Esc

Printer-friendly Version

Interactive Discussion 


\section{Abstract}

This paper investigates the binning effects on drop size distribution (DSD) measurements obtained by Joss-Waldvogel disdrometer (JWD), Precipitation Occurrence Sensor System (POSS), Thies disdrometer (Thies), Parsivel OTT disdrometer, two-dimen-

sional video disdrometer (2DVD) and optical spectro-pluviometer (OSP) instruments, therefore the evaluation comprises non-regular bin sizes and the effect of minimum and maximum measured sizes of drops. To achieve this goal, 2DVD measurements and simulated gamma size distributions were considered. The analysis of simulated gamma DSD binned according each instrument was performed to understand the role of discretisation and truncation effects together on the integral rainfall parameters and estimators of the DSD parameters. In addition, the drop-by-drop output of the 2DVD is binned to simulate the raw output of the other disdrometers which allowed us estimate sampling and binning effects on selected events from available dataset. From simulated DSD it has been found that binning effects exist in integral rainfall parameters and in the evaluation of DSD parameters of a gamma distribution. This study indicates that POSS and JWD exhibit underestimation of concentration and mean diameter due to binning. Thies and Parsivel report a positive bias for rainfall and reflectivity (reaching $5 \%$ for heavy rainfall intensity events). Regarding to DSD parameters, distributions of estimators for the shape and scale parameters were analyzed by moment, truncated moment and maximum likelihood methods. They reported noticeable differences between instruments for all methodologies of estimation applied. The measurements of 2DVD allow sampling error estimation of instruments with smaller capture areas than 2DVD. The results show that the instrument differences due to sampling were a relevant uncertainty but that concentration, reflectivity and mass-weighted diameter were

\section{AMTD}

7, 2339-2379, 2014

Binning effects on in-situ raindrop size distribution measurements

R. Checa-Garcia et al.

\section{Title Page}




\section{Introduction}

Rainfall is an integral parameter of raindrop size distribution (DSD) and is an essential element of energy and water cycles. Thus, DSD received attention from various Earth Science disciplines including cloud resolving (Li et al., 2009), climate, and weather pre5 diction models, remote sensing of precipitation (Seto et al., 2013), and hydrologic studies (Michaelides et al., 2010; Tapiador et al., 2011; Testik and Gebremichael, 2010).

The DSD is expressed as the concentration of drops per unit of volume of air at a given diameter interval. While the determination of concentration of drops relies on the measurement techniques and the instrument capacity to measure the size specthe visual presentation of the DSD depends on the preference of the size interval. In reality, the size measurements may have already been binned based on the instruments accuracy of determining the size of raindrops. In that regard, there is no preference of size interval. Only a few instruments, namely disdrometers, provide a raw output of the characteristics of each drop. The two-dimensional video disdrometer (2DVD)

15 (Kruger and Krajewski, 2002; Schönhuber et al., 2007), for instance, provides the size, fall velocity, and shape information of individual raindrops. The time stamp of these variables can be found in drop-by-drop output of the 2DVD and is valuable to assess the other disdrometers limitations due to the predetermined size interval.

Considering wide range of applications of DSD, modelers seek an analytical expression of DSD, while remote sensing applications often look after an empirical relationship between the integral parameters of the DSD, in particular between rainfall and reflectivity. Since (Marshall and Palmer, 1948) introduced a specific form of two-parameter exponential distribution and (Ulbrich, 1983) presented three-parameter gamma distribution, modelers looked for the parameters of exponential and gamma distribution 25 which is derived from disdrometer measurements. The representativeness of the disdrometer measurements for a specific model has been questioned due to highly spatial and temporal variability of DSD (Lee et al., 2009; Tokay and Bashor, 2010) and instruments limited sample cross section - typically 50 to $100 \mathrm{~cm}^{2}$ - (Smith and Kliche, 2005;

\section{AMTD}

7, 2339-2379, 2014

Binning effects on

in-situ raindrop size distribution measurements

R. Checa-Garcia et al.

\section{Title Page}

Abstract Introduction

Conclusions

Tables

References

Figures

14

4

Back

Printer-friendly Version

Interactive Discussion 
Joss and Waldvogel, 1969; Villarini et al., 2008). These factors were also concerned for the remote sensing community when the integral parameters such as well-known radar reflectivity rain rate $(Z-R)$ relation are derived from disdrometer measurements.

Measurement accuracy and the data processing is the key prior to investigating spa-

5 tial and temporal variability and sampling issues. Miriovsky et al. (2004) intended to determine the spatial variability of radar reflectivity employing five different disdrometers. This pioneer field study concluded that the measurement accuracy of disdrometers inhibited to determine the spatial variability. While there have been significant advances in the development and hardware and software improvements of optical dis10 drometers, only limited studies evaluated commercially available disdrometers through side-by-side comparative studies. Tokay et al. (2001, 2002), for instance, determined the measurement accuracy through collocated 2DVD and impact type JWD disdrometer (Joss and Waldvogel, 1969). Krajewski et al. (2006) examined the performance of 2DVD, laser optical PM Tech Parsivel disdrometer (Loffler-Mang and Joss, 2000)

and optical spectropluviometer (Hauser et al., 1984). These studies were based on two-month or less long field campaign data sets where the number of events available for comparison was rather limited. Thurai et al. (2011), on the other hand, examined performance of third generation of 2DVD, OTT Parsivel and JW disdrometers through six-month long field study, while Liu et al. (2013) compared also these disdrometers with rain gauges. Tokay et al. (2013) showed the parameters of the gamma distribution from three different disdrometers where the differences are attributed to the measurement accuracy and sampling errors.

Therefore uncertainties due to undersampling and measurement accuracy were compared on previous studies for actual disdrometers but the problem regarding the classification of continuous values of drop sizes into discrete size categories for those instruments remains open. This matter has been acknowledged by several authors (Krajewski et al., 2006; Marzuki et al., 2010, 2012) but has not been addressed systematically when comparing the results obtained from different instruments. However, different disdrometric measurements present particular characteristics that are not always
AMTD

7, 2339-2379, 2014

Binning effects on

in-situ raindrop size distribution measurements

R. Checa-Garcia et al.

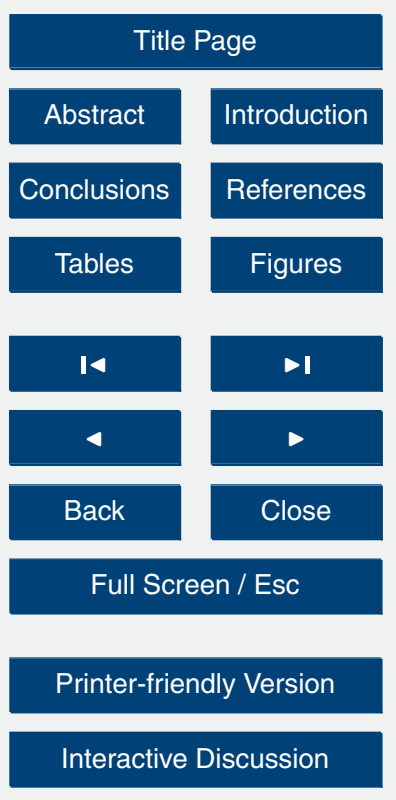


interpreted with the potential for discretisation bias in mind. The analysis of this bias is the main objective of this paper.

A pressing issue is that several sources of errors appear to be coupled in actual DSD measurements. For this reason, studies should combine different sources of data, 5 which also includes simulated DSDs. Using a specific model distribution as a part of precipitation studies allows for the analysis of statistical inference problems with a known distribution.

In sampling studies, the gamma distribution is most often used to represent the population of drop sizes. Also it allows for a reasonable representation of micro-physical 10 variations that exist in typical precipitation episodes (Kozu and Nakamura, 1991; Zhang et al., 2003; Bringi et al., 2002; Haddad et al., 2006). Thus, the first step in this study was to analyse binning effects on simulated DSD from several gamma distributions and estimate its relevance. However, studies on the estimation of DSD parameters have shown that each methodology used to estimate the DSD possesses a different behaviour with respect to the sampling problem, an issue that must be evaluated jointly with the binning processes used by each instrument. Therefore both, integral rainfall parameters bias and DSD parameters uncertainties, are addressed in the first part of the paper.

The second part of the study investigates the sampling errors in disdrometer based DSD measurements. The drop-by-drop output of 2DVD is used for this purpose. While 2DVD itself has its own sampling issues, we used 2DVD data to investigate the sampling errors of the other disdrometers. It is possible because the smaller cross sectional area of JWD, Parsivel and Thies. Therefore we were able to, (a) estimate the increase in sampling errors obtained from instruments with a smaller sensing area than that of the 2DVD device, (b) compare binning effects for sensors with the same capture area as that of the 2DVD (OSP disdrometer) and (c) analyse the binning effects between sensors with smaller sensing areas. These analyses were performed in the second part of this study.

\section{AMTD}

7, 2339-2379, 2014

Binning effects on in-situ raindrop size distribution measurements

R. Checa-Garcia et al.

\section{Title Page}
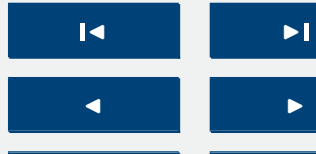

Back

Close 
Previous studies (Marzuki et al., 2010) have considered binning effects but without analysing the direct implications for a number of actual instruments. The study by (Campos and Zawadzki, 2000) compared three types of disdrometers (JWD, OSP and POSS) and concluded that discarding drops with diameters smaller than $0.7 \mathrm{~mm}$ led to 5 differences in the parameter estimates made by DSD models. More recently, (Brawn and Upton, 2008) compared JWD and Thies disdrometers showing that the additional bins of Thies for large drops affects the parameter estimation for the gamma distribution. Therefore, it is adequate to compare discretisation methods with differences in the minimum drop size considered and in bin sizes. This analysis reveals the relevance of 10 features of the binning process, including the density of bins in different parts of the spectrum of drop sizes and the effect of ignoring certain sizes, such as small sizes or drops with diameters larger than $5 \mathrm{~mm}$, as in the case of the JWD disdrometer.

This paper is organised as follows. Section 2 compares the different discretisation processes and their relevance using simulated DSD. A subsection explains the method15 ology used to generate the simulated DSD and classify into size intervals, which is followed by details of the methods used to estimate the distribution function of drop sizes. These data are analysed by comparing the integral rainfall parameter values together with the moments and maximum likelihood estimators of the gamma distribution parameters. The third section uses the 2DVD drop-by-drop dataset to compare the results obtained with different instruments by simulating that this collection of drops arrives to other devices. The last section concisely discusses the finding offering conclusive remarks. Further details about the physical assumptions made in generating the simulated DSDs are provided in the appendix.

\section{AMTD}

7, 2339-2379, 2014

Binning effects on

in-situ raindrop size distribution measurements

R. Checa-Garcia et al.

Title Page

Abstract Introduction

Conclusions

Tables

References

Figures

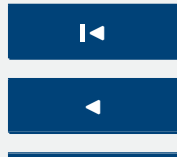

$>1$

Back

Close

\section{Full Screen / Esc}

Printer-friendly Version

Interactive Discussion 


\section{Asserting binning effects by simulated DSD}

\subsection{Generation of artificial DSDs}

It is useful to know the original size distribution when studying the bias and asymmetries in the integral rainfall parameters derived from the experimental drop size distri5 bution, which is possible through computational DSD simulations. The same technique can be applied when analysing the relevance of class intervals in the experimental DSD estimates and their integral parameters. The procedure followed herein is similar to that performed in other studies (Smith and Kliche, 2005; Kliche et al., 2008; Mallet and Barthes, 2009; Cao and Zhang, 2009). We begin with the following relationship which defines the gamma raindrop size distribution,

$N(D)=N^{(g)} D^{\mu} e^{-\lambda D}=N^{(g)} \frac{\Gamma(\mu+1)}{\lambda^{\mu+1}} f(D)=N_{t} f(D)$

Once $N^{(g)}, \mu$, and $\lambda$ are set, we have a population with an average value of $N_{t}$ drops per volume unit. The values of the parameters of the gamma distribution are chosen following the classification given by (Tokay and Short, 1996) in six different categories (Table 1) and used by other authors (Brawn and Upton, 2008; Checa and Tapiador, 2011; Checa-Garcia, 2012). A broad study (Nzeukou et al., 2004) also showed a similar classification for rain with rainfall intensity lower than $20 \mathrm{~mm} \mathrm{~h}^{-1}$ and certain variations in the gamma distribution parameters depending on the experimental sample but with a similar range of values.

The sampling process used to select the set of measured drops is based on the initial selection of a category to define the average number of drops. This figure is derived using a Poisson distribution with an average of $N_{t}$ from which the effective number of drops of $n_{t}$ collected in the disdrometer is obtained. Then, in a second step, $n_{t}$ random drop sizes that correspond to the selected gamma distribution are generated.

Binning effects on in-situ raindrop size distribution measurements

R. Checa-Garcia et al.

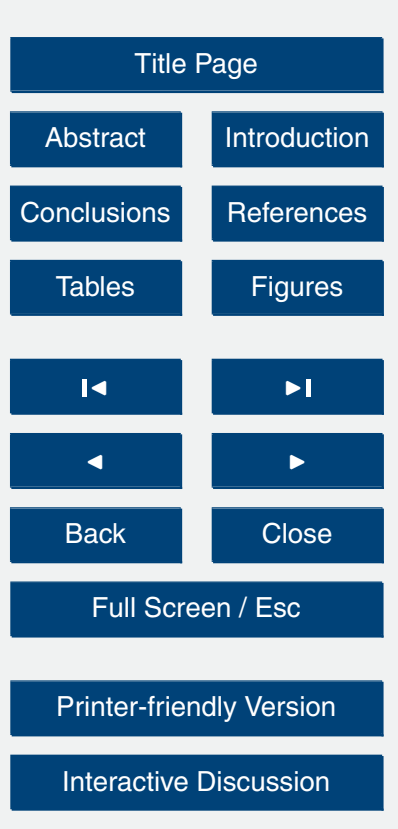




\subsubsection{Variations in the distribution parameters}

In addition to the previously simulated DSDs, we generated artificial DSDs that begin with the parameters that are defined in Table 1 but include uncertainties characterised by $\sigma_{\mu}$. This second process of DSD generation includes an extra step in which the 5 nominal values are not taken for each category but are instead generated using the Gaussian distribution $\mathcal{N}\left(\mu, \sigma_{\mu}^{2}\right)$, with an average of $\mu$ and a typical deviation of $\sigma_{\mu}$, whose values for the case of relative errors of $10 \%$ are indicated in Table 1 . This analysis is designed to consider the impact of errors of the shape parameter $(\mu)$ on the integral rainfall parameters.

\subsubsection{Classification of drops}

Eight classifications in different bins used by actual instruments were systematically analysed with respect to both optical disdrometers and impact disdrometers. The procedure is as follows: each sample is classified into the bins shown in Fig. 1, which represent the center of the class $D_{i}^{(d)}$ interval, while the class interval is given by, ${ }_{15} \Delta D_{i}^{(d)}=\left(D_{i+1}^{(d)}-D_{i}^{(d)}\right) / 2$. Frequency histograms are constructed for each sample $h_{i}^{(d)}$, leading to $N^{(d)}\left(D_{i}^{(d)}\right)=h_{i}^{(d)} / \Delta D_{i}^{(d)}$. The histograms present jumps as a result of the different values of $\Delta D_{i}^{(d)}$, and these differences are reduced when the value of the class interval is divided by the value of the size of the class interval obtaining a magnitude per unit volume and distance.

20 It is important to note that the JWD disdrometer internally classifies the drops into 127 original bins that are later classified into 20 bins. The choice of these bins varies slightly between experiments. Here, the binning shown for JWD is similar to that reported by (Caracciolo et al., 2006).

Notably, for drops with diameters larger than $2.5 \mathrm{~mm}$, the number of bins from the 25 Parsivel disdrometer includes class intervals that are greater and smaller in number than what can be relevant for higher-order moments. The Thies disdrometer (Moraes
AMTD

7, 2339-2379, 2014

Binning effects on in-situ raindrop size distribution measurements

R. Checa-Garcia et al.

Title Page

Abstract Introduction

Conclusions References

Tables Figures

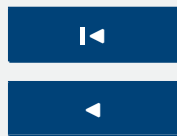

$>1$

Back

Close

Full Screen / Esc

Printer-friendly Version

Interactive Discussion 
et al., 2011) possesses different bins even though it works according to the same physical basis as the Parsivel OTT. Thies disdrometer presents class intervals that are somewhat greater than those for the Parsivel OTT ranging, from $0.5 \mathrm{~mm}$ to $2.5 \mathrm{~mm}$, while for drops with diameters larger than $5.1 \mathrm{~mm}$, the class interval is half that of the 5 Parsivel.

The case of the 2DVD is different, as it provides drop-by-drop measurements, and the binning process is usually a user-made post process. However, the most widely used binning is uniform with a width of $0.2 \mathrm{~mm}$. Additionally, to compare the results from the different disdrometers, we have also introduced artificial binning with the same 10 bins width as the 2DVD instrument but with a maximum diameter of $4.3 \mathrm{~mm}$ (referred as Right-Truncated or R-Trunc) and minimum diameter of $0.7 \mathrm{~mm}$ (referred as LeftTruncated or L-Trunc). The binning process of the POSS disdrometer is included because, while it relies on remote-sensing measurement, the results also are classified into bins, as in other instruments that are also conditioned by binning effects.

\subsection{Methods}

The methodologies utilised to analyse the binning effects of the instruments are focused on comparing the integral rainfall parameters and the DSD parameters. For the integral rainfall parameters, the most practical method is to compare the moments of the DSD retrieved by each instrument after the binning process, while for the DSD parameters it is necessary to evaluate several approaches. For this reason, two different methodologies to estimate the DSD parameters were compared: one based on the distribution moments and the other on the maximum likelihood method. The first method included a second version that considered the absence of small drop measurements by some instruments and was therefore adapted to the specific case of disdrometric 25 measurements.
AMTD

7, 2339-2379, 2014

Binning effects on

in-situ raindrop size distribution measurements

R. Checa-Garcia et al.

Title Page

Abstract Introduction

Conclusions

References

Tables Figures
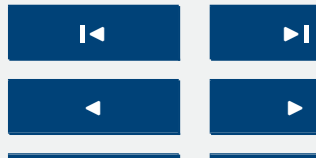

Back

Close

Printer-friendly Version

Interactive Discussion 


\subsubsection{Moment method}

The sampled and discretised gamma distribution can be estimated by different methods (Cao and Zhang, 2009). The most widely used technique is the moment method, in which three free DSD parameters are estimated from a subset of three integral rain-

5 fall parameters. The freedom in the choice of these integral parameters requires that estimates be compared from as many different subsets as possible (to achieve the best subset in each case). Given the distribution of drop size in Eq. (1), the moment of order $k$ is

$M_{k}=N^{(g)} \frac{\Gamma(\mu+k+1)}{\lambda^{\mu+k+1}}$

The methodology developed here to reach the estimate expressions is general and can in fact be applied to other distributions besides gamma distribution. We begin from the definition of a $G$ parameter as follows:

$G_{\exp }=\frac{M_{l}^{a}}{M_{k}^{b} M_{m}^{c}}$

where $I, k$ and $m$ are the orders of the integral rainfall parameters used, and $a, b$ and $c$ are three real numbers. Then by using Eq. (2):

$G\left(\mu, \lambda, N^{(g)}\right)=\left[N^{(g)}\right]^{a-b-c} \frac{\lambda^{(\mu+1)(b+c)+(k \cdot b+m \cdot c)}}{\lambda^{(\mu+1) a+l \cdot a}} g(\mu)$

20 where $g(\mu)$ is an expression involving only $\Gamma$ functions.

$g(\mu)=\frac{\Gamma^{a}(\mu+/+1)}{\Gamma^{b}(\mu+k+1) \Gamma^{c}(\mu+m+1)}$
AMTD

7, 2339-2379, 2014

Binning effects on in-situ raindrop size distribution measurements

R. Checa-Garcia et al.

Title Page

Abstract Introduction

Conclusions

References

Tables

Figures

14

4

Back

Close

Full Screen / Esc

Printer-friendly Version

Interactive Discussion 
If the following is true,

$l \cdot a=k \cdot b+m \cdot c$

then $G$ is a dimensionless quantity. If we also impose

$5 a=b+c$

then eliminating the dependence of the $G$ function on $N^{(g)}$ and eliminating the $\lambda$ factors are possible. We thus obtain an expression for $G$ that only depends on the value of $\mu$. Therefore, given the experimental values of $M_{l}, M_{k}, M_{m}$, we can determine $G_{\text {exp }}$ and obtain an estimate $\hat{\mu}\left(G_{\text {exp }}\right)$ by using the Eq. (4) with the restrictions (6) and (7).

Given $\hat{\mu}$ and the two moments (moments of a lower order usually have less severe sampling issues) from the set $(k, l, m)$, we can determine $\lambda$ and immediately $N^{(g)}$. It is important to note that $\lambda$ can be calculated using any combination of two moments from the set $(I, k$ and $m)$.

15 The analytical expressions of the estimators are given in Table 2. For the remainder of this paper, we will use the notation MMlkm to denote the method that uses the order $I, k$ and $m$ moments. This study systematically analysed the estimates using methods MM012, MM234 and MM456. The most frequently used methods in studies of disdrometers are MM234 and MM346. However, the behaviour of the last method MM346 (from the perspective of this study) can be understood from the study of the other moment methods.

\subsubsection{Truncated moment method}

Figure 2 shows that the disdrometers have minimum and maximum diameters, which indicates that the moments estimated from the sample correspond to

${ }_{25} \tilde{M}_{k}=\int_{D_{\min }}^{D_{\max }} D^{k} N(D) \mathrm{d} D$
AMTD

7, 2339-2379, 2014

Binning effects on in-situ raindrop size distribution measurements

R. Checa-Garcia et al.

Title Page

Abstract Introduction

Conclusions References

Tables Figures

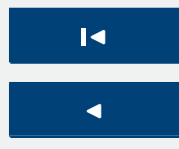

$>1$

Back

Close

\section{Full Screen / Esc}

Printer-friendly Version

Interactive Discussion 
$\tilde{M}_{k}=N^{(g)} \frac{\gamma\left(\mu+k+1, D_{\max } \lambda\right)-\gamma\left(\mu+k+1, D_{\min } \lambda\right)}{\lambda^{\mu+k+1}}$

AMTD

where $\gamma(a, l)$ is the incomplete gamma distribution that is given by

7, 2339-2379, 2014

$\gamma(\delta, I)=\int_{0}^{\delta} D^{\prime-1} e^{-D} \mathrm{~d} D$

Equation (9) is based on the assumption that $N(D)$ is a gamma distribution given by Eq. (1). Given the expressions $\widetilde{M}_{k}$, it is not possible to write $G$ (Eq. 4) as an uniparametric function of $\mu$, I and a system of two joint equations has to be solved as

${ }_{10} G_{\exp }=G(\mu, \lambda)$

$\lambda^{k-m}=\frac{\tilde{M}_{m}}{\tilde{M}_{k}}$

where the quotient $\tilde{M}_{m} / \tilde{M}_{k}$ is also a function of $\mu$ and $\lambda$. The solutions of the nonlinear system can be found numerically by the Newton-Rapshon algorithm starting 15 from the initial values of the DSD parameters given by the previous procedure. The system of equations formed by Eqs. (11) and (12) for specific moment subsets has been used in the past (Vivekanandam et al., 2004) and more recently (Kumar et al., $2010,2011)$. In our case, we evaluated the relevance of $D_{\min }$ (given that the relevance of $D_{\max }$ requires that it should be compared at all times with the large drop sampling problems). The expression used for the moments that will be introduced in Eqs. (11) and (12) is therefore

$\tilde{M}_{k}=N^{(g)} \frac{\Gamma(\mu+k+1)-\gamma\left(\mu+k+1, D_{\min } \lambda\right)}{\lambda^{\mu+k+1}}$

Binning effects on in-situ raindrop size distribution measurements

R. Checa-Garcia et al.

Title Page

Abstract Introduction

Conclusions

References

Tables

Figures

14

4

Back

Close

Full Screen / Esc

Printer-friendly Version

Interactive Discussion 


\subsubsection{Maximum Likelihood estimation}

This method is based on the existence of a likelihood function (ML) that, with a given population (a distribution function) could generate the observed sample. The ML function is defined as follows:

$5 \operatorname{ML}\left(\left\{D_{i}\right\} ; \mu, \Lambda\right)=\prod_{i=1}^{n} f\left(D_{i} ; \mu, \Lambda\right)$

for a sample of size $n$, where the two parameters $\mu$ and $\Lambda$ of the gamma function $f(D)$ are given by Eq. (1). The mathematical procedure used to determine the estimators of both parameters requires maximising function ML (Kliche et al., 2008).

\subsection{Results}

The results were structured as follows: a visual study of the artificial composite DSDs is shown. A detailed analysis of the results for the integral parameters of the precipitation in each type of disdrometer was presented, considering also the relevance on an uncertainty on the shape parameter of the DSD. Regarding the DSD parameters, different estimation methods were compared.

\subsubsection{Overview of composite DSDs}

The generated DSDs are similar to the underlying gamma distribution functions if we analyse the average DSD for a sufficient number of cases (a stable form is usually reached after accumulating $50 \mathrm{DSDs}$ ). There is the possibility that slight instabilities may remain for drop diameters of $D<1 \mathrm{~mm}$ after the binning processes (see Fig. 1 Bottom panel), and depending on the rain intensity, variations may also persist for large drop sizes (of diameters $\gtrsim 4 \mathrm{~mm}$ ), similar to real cases.
AMTD

7, 2339-2379, 2014

Binning effects on in-situ raindrop size distribution measurements

R. Checa-Garcia et al.

\section{Title Page}

\section{Full Screen / Esc}

Printer-friendly Version

Interactive Discussion 
For typical stratiform rain situations, the use of the classifications in Table $1 \mathrm{com}$ bined with the temporal series of precipitation intensity values produces monotonous composite DSDs similar to those of the experimental studies.

\subsubsection{Integral rainfall parameters}

5 The first issue is the relevance of the binning process to the estimation of the various integral parameters for the precipitation, which we write generically as

$M_{k}=\int_{0}^{\infty} D^{k} N(D) \mathrm{d} D \simeq \sum_{i=0}^{N_{\text {bins }}} N\left(D_{i}\right) D_{i}^{k} \Delta D_{i}$

The usual approach is to approximate the integral using the sum over the disdrometer 10 bins as indicated in (15). The values of $D_{\min }=D_{0}-\Delta D_{i} / 2$ and $D_{\max }=D_{N_{\text {bins }}}-\Delta D_{i} / 2$, as well as the bin density in specific zones of the spectrum, led to systematic deviations in the estimates for the hypothetical underlying population values of $M_{k}$. This clarifies the results in Fig. 2 based on Fig. 3, where the relevance of each zone of the spectrum of sizes is observed in the DSD moments for each category of rain intensity (under the assumption of a uniform binning process). These results should be interpreted together with the general bias properties of the moment estimators (Smith and Kliche, 2005). It is acknowledged that due to sampling, the integral rainfall parameters of the gamma distribution are biased and the differences between the analytical value and sampled value increases with the order of the moment. The ratio between sampled and analytical values is shown in Fig. 2 .

The first implication observed in Fig. 2 is a bias at the moment $M_{k}$, which depends on the category but has systematic characteristics. Disdrometers that do not have bins with small diameters underestimate the first moments (most notably in cases of slight precipitation intensity in which the differences can be greater than $20 \%$ ), while the

25 Parsivel OTT and Thies overestimate the greater moments (note that because of the sampling bias the effective deviation of Parsivel for higher-order moments due only to 2352
AMTD

7, 2339-2379, 2014

Binning effects on

in-situ raindrop size distribution measurements

R. Checa-Garcia et al.

Title Page

Abstract Introduction

Conclusions

Tables

References

Figures

14

4

Back

Close

Full Screen / Esc

Printer-friendly Version

Interactive Discussion
$>1$

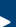

Sc ion 
binning is slightly less than that shown in the figures). For those disdrometers, this is explained by the fact that they have fewer bins in the 2 to $4 \mathrm{~mm}$ interval. The effect of the difference on the size range of this bin quantity is also observed in POSS disdrometers for moderate to heavy intensities. In general, for the intense rain case, the differences in 5 the smaller moments are smaller because the DSD has a less significant role for small drops. Only in the case of the OSP and Left-Truncated do these differences persist and interfere with comparisons for smaller diameters.

When an uncertainty is introduced in $\mu$ (representing possible small fluctuations in the shape parameter of the gamma distribution) the results are analogous, but the

10 sampling bias obtained is mainly increased for intense rainfall, while the binning effects seem additive regarding this kind of sampling issue.

\subsection{DSD parameter estimates}

Comparing the performance of different estimation methods for DSDs implies deciding what uncertainties in the estimation can have a greater effect in practice, which can 5 depend on the specific use of the DSD measurements. One of the most commonly used methods is the mean squared error (MSE), defined for the case of the $\mu$ parameter as $\operatorname{MSE}_{\mu}(\hat{\mu})=\left\langle(\hat{\mu}-\mu)^{2}\right\rangle=\operatorname{Var}(\hat{\mu})_{\mu}-\operatorname{bias}(\hat{\mu})_{\mu}$, where the bias is the deviation from the average: $\operatorname{bias}(\hat{\mu})_{\mu}=\langle\hat{\mu}\rangle-\mu$ which is another statistic used to determine the performance of the estimation method. Each estimator $\hat{\mu}$ would have an average quadratic 20 error and a bias that would depend (or not) on the value of $\mu$. Worse difficulties exist, such as having to characterise the estimator more broadly using other statistics (if the distribution of values of $\hat{\mu}$ presents peculiar properties) or including more robust estimators than usual. One practical way of comparing the different estimators based on our objective is to use box-plot diagrams that show in compactly and visually many
AMTD

7, 2339-2379, 2014

Binning effects on in-situ raindrop size distribution measurements

R. Checa-Garcia et al.

\section{Title Page}

Abstract Introduction

Conclusions

Tables

References

Figures

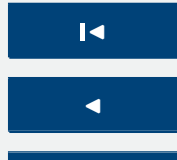

$>1$

Back

Close

Printer-friendly Version

Interactive Discussion 


\subsubsection{Moment method}

For the case in which the $N(D)$ is estimated, understanding the relevance of binning for each of the existing methodologies is significant. The different method estimates for a broad sample of DSDs and the corresponding statistical properties were studied for 5 very light rain, moderate rain and very heavy rain categories and were compared to an estimate that directly uses the sample unclassified in bins whose error originates only from the sampling, rather than performing discretisation.

The statistical properties of the estimator $\hat{\mu}$ are shown in the Fig. 4 . To build the boxplots, 5000 different samples were considered (more than $5 \times 10^{5}$ drops were analysed in each case). This allowed us to assert which moment method is preferred according to the rain intensity and the several binning processes.

As shown in the Fig. 4, for the MM456 case, the binning is less relevant than in other cases, as the sampling process masked the discretisation process, although major errors exist in the accuracy of the estimates. Cases MM234 and MM012 are more 15 sensitive to the concrete characteristics of the disdrometer, implying that the bin selection of, for example, the JWD, POSS or Parsivel OTT disdrometers produces sensible deviations. The MM346 (not shown) exhibits properties between MM234 and MM456 cases.

\subsubsection{Truncated moment method}

20 The truncated moment method, which incorporates a hypothesis regarding the size interval in the DSD estimation process, is used when DSD parameter prediction problems arise for the traditional moment method in which the bins fail to measure or undervalue small drops. We have restricted these analyses to the MM012 and MM234 methods, which exhibit sensitivity to the smaller diameters, and we report a comparison of the JWD, OSP and Parsivel disdrometers. The results are shown on Fig. 5.

The distribution of the resulting parameters has an average value that is similar to the real value and a distribution that is similar to that derived from the sampling process.
AMTD

7, 2339-2379, 2014

Binning effects on

in-situ raindrop size distribution measurements

R. Checa-Garcia et al.

Title Page

Abstract Introduction

Conclusions

Tables

References

Figures

14

4

Back

Close
$>$ I

$>$

Printer-friendly Version

Interactive Discussion

Full Screen / Esc

Interactive Discussion 
The estimates change from overestimates to underestimates with the significant caveat that the distribution of values in the case of parameter $\lambda$ is notably biased. Apparently, the median is preferred over the average for this estimate.

This caveat is explained by a significant growth in the marginal distribution values 5 (outliers) under a calculation that progressively involves up to 5000 DSDs in each of the categories. The averages in the heavy and very heavy cases are notably displaced, an aspect that is not observed in the remaining categories. These observations indicate that, the use of the median appears to be more robust than the use of the average, and the robust alternative is to use a trimmed mean or a Winsorised mean.

\subsubsection{Maximum Likelihood estimation method}

The problem for small drops persists in the maximum likelihood estimation (MLE) method, as reported in other studies (Mallet and Barthes, 2009; Cao and Zhang, 2009). Here, the objective of applying the MLE method is mainly to observe if the distributions of estimator parameters of the DSD are similar to those obtained with the moment

\section{Sampling vs. binning effects on experimental DSDs}

DSD measurements must deal with both, sampling issues and binning processes. The measurement of 2DVD disdrometers offers us the possibility of addressing both issues. In the following sections are explained the properties of the data-set and the methods used in the analysis are explained.
AMTD

7, 2339-2379, 2014

Binning effects on

in-situ raindrop size distribution measurements

R. Checa-Garcia et al.

\section{Title Page}

\section{Full Screen / Esc}

Printer-friendly Version

Interactive Discussion 


\subsection{Experimental data: 2DVD disdrometer}

The dataset was measured by a 2DVD video disdrometer from the Mid-Latitude Continental Convective Clouds Experiment (MC3E) in Central Oklahoma during AprilJune 2011. The 2DVD disdrometer is an advanced optical instrument that measures

5 three properties (drop size, vertical velocity and shape) of the collection of drops that cross the sampling area.

One primary advantage of the 2DVD instrument is the possibility of recording a dropby-drop database. This property was used to analyse different binning processes with real data. With the goal of obtaining a consistent dataset, a filtering technique was 10 applied to filter spurious drops whose terminal velocities differ by more than $50 \%$ from from Gunzer and Kinzer (1949) laboratory measurements of fall velocities in still air.

\subsection{Generating DSDs detected by different instruments}

To be able to faithfully simulate the binning process of different disdrometers, we need to include information about the sensing areas, such as that shown in Table 3. For this 15 reason, the collection of drops detected by different instruments is estimated by a twostep method: (a) using the drop-by-drop dataset a random subset with a number of drops proportional to the sampling area is selected - see Table 3 -; (b) classification into bins according to the disdrometers is performed.

In the case in which the sensing area is smaller than that of the 2DVD, it was neces20 sary to perform an estimation of the sampling error. This was performed by a standard
re-sampling bootstrap technique (Efron, 1979). The idea is to perform the steps (a) and
(b) $M$ times to be able to calculate the reliable estimator characteristics of each instrument for the underlying population of drops. The number of random subsets (DSDs) $M$ of the original 2DVD measurement was chosen to be 50 samples for the 100 drops cases and 100 samples for the 1000 drops cases (with a linear increase of $M$ with the number of drops). This allowed us to estimate both the average value measured by $M$ identical instruments with smaller sampling areas and estimate the standard deviation
AMTD

7, 2339-2379, 2014

Binning effects on in-situ raindrop size distribution measurements

R. Checa-Garcia et al.

Title Page

Abstract Introduction

Conclusions

Tables References Figures

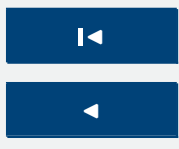
$>$ I

Back Close

Printer-friendly Version

Interactive Discussion 
of the under-sampling. An analysis of 6 events was performed; the details of those events are provided in Table 4.

\subsection{Integral rainfall values for 2DVD measurements}

It is interesting to compare several integral rainfall parameters typically used in DSD 5 studies. To achieve this objective, the total concentration of drops, rainfall intensity, reflectivity and mass-weighted diameter $\left(M_{4} / M_{3}\right)$ were compared.

The first step is to understand the role of the sensing area. The challenge in determining the sampling error characteristics of a 2DVD sensing area is usually met by comparing identical collocated instruments. In our case, given an isolated instrument it is still possible to appreciate the role played by the sampling errors in devices with smaller sensing areas. To better understand these sampling issues, a relationship between the mean values and the standard deviation obtained by the re-sampling technique is shown in Fig. 7. The results show similar patterns for the Parsivel OTT, JWD and Thies instruments; however they also show slight differences. In the case of the 15 Thies larger sampling errors (more obvious in concentration) are observed due to the smaller sensing area of this disdrometer. A roughly multiplicative bias appears for the concentration, rainfall and reflectivity, while in the case of $D_{\text {mass }}$, which is the quotient of two consecutive DSD moments, it would be difficult to model the relationship between mean values and standard deviation.

20 The second step is to evaluate the binning effects. We study the mean values of the integral rainfall parameters after the re-sampling process because they are supposed to be less dependent on sample-by-sample deviations. Therefore, they should be more efficient in reveling the real differences due to binning. To address those binning effects we used the relative difference with respect to the value of 2DVD, $\left(\bar{X}_{D}-X_{2 \mathrm{DVD}}\right) / X_{2 \mathrm{DVD}}$

where the disdrometer $D$ was successively OSP, Thies, Parsivel OTT and JWD, and $X$ is an integral rainfall parameter. The collection of results is shown Fig. 8, where the deviations between relative differences are mainly due to binning effects (an analogous result for simulated DSDs is shown in the Fig. 3).

2357
AMTD

7, 2339-2379, 2014

Binning effects on

in-situ raindrop size distribution measurements

R. Checa-Garcia et al.

Title Page

Abstract Introduction

Conclusions

Tables References Figures

14

4

Back

Close

Printer-friendly Version

Interactive Discussion 
The most obvious effect was that of OSP instrument showing that discarded drops with diameters of $0.6 \mathrm{~mm}$ indicate relevant differences, as expected from the previous analysis with simulated DSDs. The Thies presents a faithful correspondence with the 2DVD with respect to concentration, in contrast with the JWD and Parsivel OTT. How5 ever, the Fig. 8 also shows that Thies presents a tendency for positive bias with respect to Rainfall and Reflectivity, as observed for simulated DSD. These facts are more obvious when histograms of the relative difference or box-plots are compared. The Fig. 9 supports the notion that the deviations present in the simulated gamma DSD persist in DSD measurements. However, it is important to note that while two different collo10 cated disdrometers should exhibit binning effects, these effects should be considered an asymptotic statistical property. As a result, two disdrometers may have differences due to the sampling masking the binning effects but data accumulated over large periods or statistical analyses performed on an entire dataset show binning effects. This is illustrated in Fig. 9, where the deviations between mean values demonstrate the role 15 of binning on statistical analysis.

\section{Summary and conclusions}

The simulation of drop size distributions according to the size classifications performed by actual instruments determined the significance of the binning process. The sensitivity of each moment and different region of the drop size spectrum explains systematic 20 deviations in the estimation of moments. A smaller density of bins for drop diameters of $D>3 \mathrm{~mm}$ implies a systematic reflectivity overestimation of approximately $5 \%$, which is additive with respect to other sources of error, such as sampling, and the uncertainties that arise due to errors in the parameter estimates that define the DSD.

Deviations in the moments depend on both the intensity of the precipitation (through 25 the category classifications used in this study) and on the order of the analysed moment, both of which will be considered in the error evaluations in the moment estimations from DSD modelling. The relevance on the DSD parameter estimates of the
AMTD

7, 2339-2379, 2014

Binning effects on

in-situ raindrop size distribution measurements

R. Checa-Garcia et al.

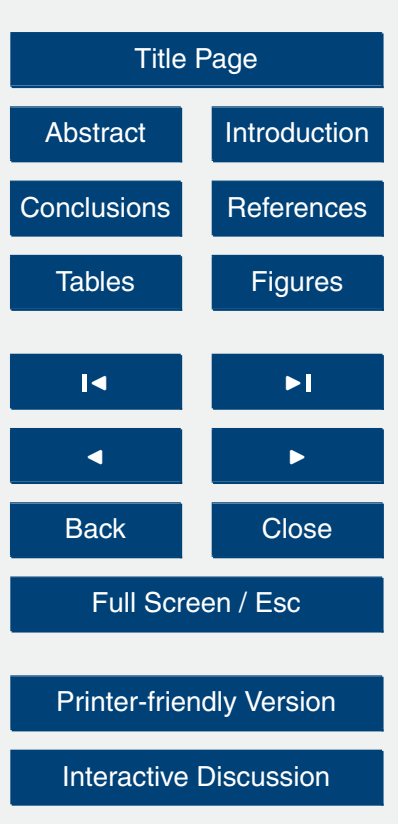

Interactive Discussion 
binning process has also been evaluated, demonstrating that measurement problems for small drops are the most relevant, as they affect the estimated values of the moment method and the method based on maximum verosimilitude.

Estimates can be improved with the truncated moment method (and MLE analogue), 5 but this method requires robust estimators for the distribution of the various parameter estimates due to the presence of outliers, especially for the parameter $\lambda$ of a gamma distribution.

Technically, the errors of each type of instrument should be analysed using experimental designs like Tokay et al. (2005). The underestimation of the number of small drops appears to be a common characteristic for the majority of disdrometers, while the overestimation of large drops is characteristic of traditional optical spectropluviometers. Given that comparing the different devices errors for each instrument with sampling and discretisation issues obscures the ability to identify the source of the error, a main question to address in future research is the limit whether the analysis of the binning process remains necessary despite the introduction of these instrumental errors. The analyses conducted here demonstrate that experiments comparing instruments with different bins should be performed in a preliminary study on what methodologies are the most appropriate in accordance with the objectives of each experiment and, above all, with the characterisation of errors.

\section{Appendix A}

\section{About the generation of artificial DSDs}

The proposed methodology is based on the modelling of precipitation as a homogeneous Poisson process which is the preferred method in the literature. The methodology is based on the assumption of stationary rain, a physical situation that arises in 25

\section{AMTD}

7, 2339-2379, 2014

Binning effects on in-situ raindrop size distribution measurements

R. Checa-Garcia et al.

\section{Title Page}

\section{Full Screen / Esc}

Printer-friendly Version

Interactive Discussion 
a lower level of statistical fluctuations than that observed in more general situations, and as consequence it may provide a lower threshold on the bias. In our study regarding the relevance of binning, the differentiation between homogeneously distributed rain and rain distributed in clusters is not necessary; in both cases, we expect the binning process to produce the same level of error relative to other error sources.

We could include an estimate of the sampled volume (given a collection area of $S$ and a measurement time of $T$ ) for each diameter (Uijlenhoet and Pomeroy, 2001; Mallet and Barthes, 2009) based on a value of $v(D)$ as STV $(D)$, which is calculated using $v(D)=\delta D^{\epsilon}$. Some authors (Moisseev and Chandrasekar, 2007) do not consider this 10 distinction relevant for the majority of analyses. The procedure introduced by (Mallet and Barthes, 2009) involves choosing a concrete relationship, $v(D)$, and is useful in the case of JWD-type disdrometers, which presume an specific $v(D)$ relationship in the measurement process. However, this approach is less practical for optical disdrometers that measure terminal drop velocity. These instruments usually include a tolerance interval of $50-60 \%$ over a given $v(D)$ relationship, which in practice can eliminate the differences in sampling volumes between adjacent bins. Above all, this approach would make the analysis process dependent on the velocity distribution generation hypothesis for each diameter. We also observed that the sampled function, including $v(D)$, is analogous to the former function, $f(D)$, but with $\tilde{\mu}=\mu+\epsilon$ and $\tilde{N}_{t}=N_{t} \delta S T$. In our case, we chose a constant volume sampling solution (as we could attempt multiple combinations of $N_{t}$ and $\mu$ ) and we also introduced the possibility of moderated variations for $\mu$.

Other authors (Cao and Zhang, 2009) introduce an observational error for each bin based on the comparison of two collocated disdrometers. In our case, it is inconvenient to include this type of error from the beginning. We compared the binning processes of disdrometers with different physical measurement processes that give rise to slightly different observational errors but do not alter the discretisation of the spectrum.

Regarding with the values of $\sigma_{\mu}=10 \%$ proposed. They are moderate in contrast to other references (Moumouni et al., 2009) where they can reach $40-50 \%$ of the average
AMTD

7, 2339-2379, 2014

Binning effects on

in-situ raindrop size distribution measurements

R. Checa-Garcia et al.

Title Page

Abstract Introduction

Conclusions

Tables References Figures

14

4

Back

Close

Printer-friendly Version

Interactive Discussion 
value. The main difference in our case is that we deal with errors within each category of rainfall intensity, while other studies assign variations for whole events. These typical moderated variations allow for the implicit inclusion of possible variations in sampling volumes, as well as variations over the intensity intervals of the studied precipitation. 5 In this regard, with (Nzeukou et al., 2004) as a reference, the average values for four different campaigns are similar to those included in Table 1, while the differences in the values of the $\mu$ and $\lambda$ parameters range from $20 \%$ to $25 \%$.

Acknowledgements. A relevant part of this study was done by Ramiro Checa-Garcia as part of his PhD with affiliation at Faculty of Environmental Sciences and Biochemistry (UCLM), 10 therefore is gratefully acknowledged the funding from project PPII10-0162-554 (JCCM). The raw 2DVD data set were provided by Ali Tokay from the Midlatitude Continental Convective Clouds Experiment (MC3E) which took place in central Oklahoma during the April-June 2011 period (http://gpm.nsstc.nasa.gov/mc3e/). Ramiro Checa-Garcia acknowledges Jan-Bernd Schröer for bring up attention to the binning of Parsivel OTT. Ramiro Checa-Garcia also ac15 knowledges the support by Deutsche Forschungsgemeinschaft and Open Access Publishing Fund of Karlsruhe Institute of Technology.

\section{Author contribution.}

R. Checa-Garcia outlined and designed the research presented including the mathematical 20 details, software design and calculations, together with datasets processing. A. Tokay provided 2DVD raw dataset and Level 2 processed data necessary to check R. Checa-Garcia's software, contributed to write the introduction, and provided comments and revisions to all sections. F. J. Tapiador provided funding from JCCM project (and commented on previous versions of Figs. 1 and 2). R. Checa-Garcia wrote and prepared this manuscript, including all figures and tables.

The service charges for this open access publication have been covered by a Research Centre of the Helmholtz Association.

\section{AMTD}

7, 2339-2379, 2014

Binning effects on in-situ raindrop size distribution measurements

R. Checa-Garcia et al.

\section{Title Page}
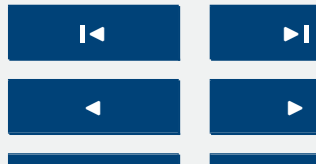

\section{Full Screen / Esc}

Printer-friendly Version

Interactive Discussion 


\section{References}

Brawn, D. and Upton, G.: Estimation of an atmospheric gamma drop size distribution using disdrometer data, Atmos. Res., 87, 66-79, doi:10.1016/j.atmosres.2007.07.006, 2008. 2344, 2345

5 Bringi, V. N., Huang, G., Chandrasekar, V., and Gorgucci, E.: A methodology for estimating the parameters of a gamma raindrop size distribution model from polarimetric radar data: application to a squall-line event from the TRMM/Brazil Campaign, J. Atmos. Ocean. Tech., 19, 633-645, doi:10.1175/1520-0426(2002)019<0633:AMFETP>2.0.CO;2 , 2002. 2343

Campos, E. and Zawadzki, I.: Instrumental uncertainties in Z-R Relations, J. Appl. Meteorol., 39, 1088-1102, doi:10.1175/1520-0450(2000)039<1088:IUIZRR>2.0.CO;2, 2000. 2344, 2371

Cao, Q. and Zhang, G.: Errors in estimating raindrop size distribution parameters employing disdrometer and simulated raindrop spectra, J. Appl. Meteorol. Climatol., 48, 406-425, doi:10.1175/2008JAMC2026.1,2009. 2345, 2348, 2355, 2360

15 Caracciolo, C., Prodi, F., and Uijlenhoet, R.: Comparison between Pludix and impact/optical disdrometers during rainfall measurement campaigns, Atmos. Res., 82, 137163, doi:10.1016/j.atmosres.2005.09.007, 2006. 2346

Checa, R. and Tapiador, F. J.: A maximum entropy modelling of the rain drop size distribution, Entropy, 13, 293-315, 2011. 2345

20 Checa-Garcia, R.: First measurement of the small-scale spatial variability of the raindrop size distribution: results from a crucial experiment and maximum entropy modelling (arXiv:1306.5649), Ph. D. Thesis, Spain, available at: http://arxiv.org/abs/1306.5649, 2012. 2345

Efron, B.: Bootstrap methods: another look at the jackknife, Ann. Stat., 7, 1-26, doi:10.1214/aos/1176344552, 1979. 2356

Haddad, Z. S., Meagher, J. P., Durden, S. L., Smith, E. A., and Im, E.: Drop size ambiguities in the retrieval of precipitation profiles from dual-frequency radar measurements, J. Atmos. Sci., 63, 204-217, 2006. 2343

Hauser, D., Amayenc, P., Nutten, B., and Waldteufel, P.: A new optical instrument for simultaneous measurement of raindrop diameter and fallspeed distributions, J. Atmos. Ocean. Tech., 1, 256-269, doi:10.1175/1520-0426(1984)001<0256:ANOIFS>2.0.CO;2, 1984. 2342
AMTD

7, 2339-2379, 2014

Binning effects on

in-situ raindrop size

distribution

measurements

R. Checa-Garcia et al.

Title Page

Abstract

Introduction

Conclusions

References

Tables

Figures

14

4

Back

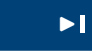

$>$

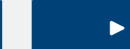

(

Full Screen / Esc

Printer-friendly Version

Interactive Discussion 
Jameson, A. R. and Kostinski, A. B.: When is rain steady?, J. Appl. Meteorol., 41, 83-90, 2002. 2359

Joss, J. and Waldvogel, A.: Raindrop size distribution and sampling size errors, J. Atmos. Sci., 26, 566-569, 1969. 2342

5 Kliche, D. V., Smith, P. L., and Johnson, R. W.: L-moment estimators as applied to gamma drop size distributions, J. Appl. Meteorol. Climatol., 47, 3117-3130, doi:10.1175/2008JAMC1936.1, 2008. 2345, 2351

Kozu, T. and Nakamura, K.: Rainfall parameter estimation from dual-radar measurements combining reflectivity profile and path-integrated attenuation, J. Atmos. Ocean. Tech., 8, 259$10 \quad 270,1991.2343$

Krajewski, W., Kruger, A., Caraicciolo, C., Golé, P., Barthes, L., Creutin, J., Delahaye, J., Nikolopoulus, E., Odgen, F., and Visoni, J.: DEVEX-disdrometer evaluation experiment: basic results and implications for hydrologic studies, Adv. Water Resour., 1, 311-325, doi:10.1016/j.advwatres.2005.03.018, 2006. 2342

Kruger, A. and Krajewski, W. F.: Two-dimensional video disdrometer: a description, J. Atmos. Ocean. Tech., 19, 602-617, doi:10.1175/1520-0426(2002)019<0602:TDVDAD>2.0.CO;2, 2002. 2341

Kumar, L., Lee, Y. H., and Ong, J. T.: Truncated Gamma Drop Size Distribution Models for Rain Attenuation in Singapore, Antennas and Propagation, IEEE Transactions on, 58, 1325 $20 \quad$-1335, doi:10.1109/TAP.2010.2042027, 2010. 2350

Kumar, L., Lee, Y. H., and Ong, J. T.: Two-Parameter Gamma Drop Size Distribution Models for Singapore, Geoscience and Remote Sensing, IEEE Transactions on, 49, 3371-3380, 2011. 2350

Larsen, M. L., Kostinski, A. B., and Tokay, A.: Observations and Analysis of Uncorrelated Rain., J. Atmos. Sci., 62, 4071-4083, doi:10.1175/JAS3583.1, 2005. 2359

Lee, C. K., Lee, G., Zawadzki, I., and Kim, K.-E.: A preliminary analysis of spatial variability of raindrop size distributions during stratiform rain events, J. Appl. Meteorol. Climatol., 48, 270, doi:10.1175/2008JAMC1877.1, 2009. 2341

Li, X., Tao, W.-K., Khain, A. P., Simpson, J., and Johnson, D. E.: Sensitivity of a cloud-resolving 30 model to bulk and explicit bin microphysical schemes, Part II: Cloud microphysics and storm dynamics interactions, J. Atmos. Sci., 66, 22-40, doi:10.1175/2008JAS2647.1, 2009. 2341

Liu, X. C., Gao, T. C., and Liu, L.: A comparison of rainfall measurements from multiple instruments, Atmos. Meas. Tech., 6, 1585-1595, doi:10.5194/amt-6-1585-2013, 2013. 2342

Binning effects on in-situ raindrop size distribution measurements

R. Checa-Garcia et al.

Title Page

Abstract Introduction

Conclusions

References

Tables Figures

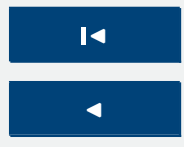

$>$ I

Back

Close

Full Screen / Esc

Printer-friendly Version

Interactive Discussion 
Loffler-Mang, M. and Joss, J.: An optical disdrometer for measuring size and velocity of hydrometeors, J. Atmos. Ocean. Tech., 17, 130-139, doi:10.1175/15200426(2000)017<0130:AODFMS>2.0.CO;2, 2000. 2342, 2371

Mallet, C. and Barthes, L.: Estimation of gamma raindrop size distribution parameters: 5 statistical fluctuations and estimation errors, J. Atmos. Ocean. Tech., 26, 1572-1584. doi:10.1175/2009JTECHA1199.1, 2009. 2345, 2355, 2360

Marshall, J. S. and Palmer, W. M.: The distribution of raindrops with size, J. Atmos. Sci., 5, 165-166, 1948. 2341

Marzuki, M., Randeu, W. L., Kozu, T., Shimomai, T., Schönhuber, M., and Hashiguchi, H.: Estimation of raindrop size distribution parameters by maximum likelihood and L-moment methods: effect of discretization, Atmos. Res., 112, 1-11, 2012. 2342

Marzuki, M., Randeu, W., Schoandnhuber, M., Bringi, V., Kozu, T., and Shimomai, T.: Raindrop size distribution parameters of distrometer data with different bin sizes, IEEE T. Geosci. Remote, 48, 3075-3080, 2010. 2342, 2344

Michaelides, S., Levizzani, V., Anagnostou, E., Bauer, P., Kasparis, T., and Lane, J. E.: Precipitation: measurement, remote sensing, climatology and modeling, Atmos. Res., 95, 512-533, 2010. 2341

Miriovsky, B., Bradley, A., Eichinger, W., Krajewski, W. F., Kruger, A., and Nelson, B.: An experimental study od small-scale variability of radar reflectivity using disdrometer observations, J. Appl. Meteorol., 43, 106-118, doi:10.1175/1520-0450(2004)043<0106:AESOSV>2.0.CO;2, 2004. 2342

Moisseev, D. N. and Chandrasekar, V.: Examination of the shape-slope relation suggested for drop size distribution parameters, J. Atmos. Ocean. Tech., 24, 847-855, 2007. 2360

Moraes, R. P. D., de Cunha, L. K., and Krajewski, W. F.: Assessment of the Thies optical disdrometer performance, Atmos. Res., 101, 237-255, 2011. 2346

Moumouni, S., Gosset, S., and Houngninou, E.: Main features of rain drop size distributions observed in Benin, West Africa, with optical disdrometers, Geophys. Res. Lett., 35, L23807, doi:10.1029/2008GL035755, 2008. 2360

Nzeukou, A., Sauvageot, H., Delfin Ochou, A., and Mouhamed Fadel Kebe, C.: Raindrop size 30 distribution and radar parameters at Cape Verde, J. Appl. Meteorol., 43, 90-105, 2004. 2345, 2361

\section{AMTD}

7, 2339-2379, 2014

Binning effects on in-situ raindrop size distribution measurements

R. Checa-Garcia et al.

Title Page

Abstract Introduction

Conclusions

References

Tables Figures

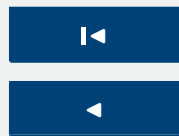

$>1$

Back

Close

Full Screen / Esc

Printer-friendly Version

Interactive Discussion 
Schönhuber, M., Lammer, G., and Randeu, W. L.: One decade of imaging precipitation measurement by 2D-video-distrometer, Adv. Geosci., 10, 85-90, doi:10.5194/adgeo-10-85-2007, 2007. 2341

Seto, S., Iguchi, T., and Oki, T.: The basic performance of a precipitation retrieval algorithm for 5 the global precipitation measurement mission's single/dual-frequency radar measurements, IEEE T. Geosci. Remote, 51, 5239-5251, 2013. 2341

Sheppard, B. and Joe, P.: Comparison of raindrop size distribution measurements by a JossWadvogel disdrometer, a PMS 2DG spectrometer and a POSS Doppler radar., J. Atmos. Ocean. Tech., 11, 874-887, 1994. 2371

10 Smith, P. L. and Kliche, D. V.: The bias in moment estimators for parameters of drop size distribution functions: sampling from exponential distributions, J. Appl. Meteorol., 44, 11951205, 2005. 2341, 2345, 2352

Tapiador, F. J., Hou, A. Y., de Castro, M., Checa, R., Cuartero, F., and Barros, A. P.: Precipitation estimates for hydroelectricity, Energ. Environ. Sci., 4, 4435-4448, 2011. 2341

15 Testik, F. Y. and Gebremichael, M. (Eds.): Rainfall: State of the Science, vol. 191, AGU, Washington DC, 2010. 2341

Thurai, M., Petersen, W. A., Tokay, A., Schultz, C., and Gatlin, P.: Drop size distribution comparisons between Parsivel and 2-D video disdrometers, Adv. Geosci., 30, 3-9, doi:10.5194/adgeo-30-3-2011, 2011. 2342

20 Tokay, A. and Bashor, P. G.: An experimental study of small-scale variability of raindrop size distribution, J. Appl. Meteorol. Climatol., 49, 2348-2365, 2010. 2341

Tokay, A. and Short, D. A.: Evidence from tropical raindrop spectra of the origin of rain from stratiform versus convective clouds, J. Appl. Meteorol., 35, 355-371, 1996. 2345, 2367

Tokay, A., Kruger, A., and Krajewski, W.: Comparison of drop size distribution measurements by impact and optical disdrometers, J. Appl. Meteorol., 40, 2083-2097, 2001. 2342

Tokay, A., Kruger, A., Krajewski, W. F., Kucera, P. A., and Filho, A. J. P.: Measurements of drop size distribution in the southwestern Amazon basin, J. Geophys. Res.-Atmos., VOL. 107, NO. D20, 8052, doi:10.1029/2001JD000355, 2002. 2342

Tokay, A., Bashor, P. G., and Wolff, K. R.: Error characteristics of rainfall measure30 ments by collocated Joss Waldvogel disdrometers, J. Atmos. Ocean. Tech., 22, 513-527, doi:10.1175/JTECH1734.1, 2005. 2359

\section{AMTD}

7, 2339-2379, 2014

Binning effects on in-situ raindrop size distribution measurements

R. Checa-Garcia et al.

\section{Title Page}

Abstract

Introduction

Conclusions

References

Tables

Figures

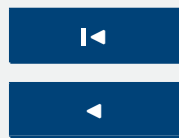

$>$ I

Back

Close

Full Screen / Esc

Printer-friendly Version

Interactive Discussion 
Tokay, A., Petersen, W. A., Gatlin, P., and Wingo, M.: Comparison of raindrop size distribution measurements by collocated disdrometers, J. Atmos. Ocean. Tech., 30, 1672-1690, doi:10.1175/JTECH-D-12-00163.1, 2013. 2342

Uijlenhoet, R. and Pomeroy, J. H.: Raindrop size distributions and radar reflectivity-rain rate 5 relationships for radar hydrology, Hydrol. Earth Syst. Sci., 5, 615-628, doi:10.5194/hess-5615-2001, 2001. 2360

Uijlenhoet, R., Porra, J., Torres, D., and Creutin, J.: Analytical solutions to sampling effects in drop size distribution measurements during stationary rainfall: estimation of bulk rainfall variables, J. Hydrol., 328, 65-82, 2006. 2359

Ulbrich, C. W.: Natural variations in the analytical form of the raindrop size distribution, J. Appl. Meteorol., 22, 1764-1775, 1983. 2341, 2372

Villarini, G., Mandapaka, P. V., Krajewski, W. F., and Moore, R. J.: Rainfall and sampling uncertainties: a rain gauge perspective, J. Geophys. Res.-Atmos., 113, D11102, doi:10.1029/2007JD009214, 2008. 2342

Vivekanandam, J., Zhang, G., and Brandes, E.: Polarimetric radar estimators based on a constrained gamma drop size distribution model., J. Appl. Meteorol., 43, 217-230, 2004. 2350

Zhang, G., Vivekanandan, J., Brandes, E. A., Meneghini, R., and Kozu, T.: The shape-slope relation in observed gamma raindrop size distributions: statistical error or useful information?, J. Atmos. Ocean. Tech., 20, 1106-1119, 2003. 2343
AMTD

7, 2339-2379, 2014

Binning effects on in-situ raindrop size distribution measurements

R. Checa-Garcia et al.

Title Page

Abstract Introduction

Conclusions

References

Tables

Figures

14

$>$ I

4

Back

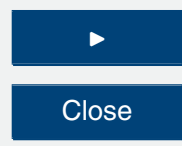

Full Screen / Esc

Printer-friendly Version

Interactive Discussion 
AMTD

7, 2339-2379, 2014

\section{Binning effects on in-situ raindrop size distribution measurements}

R. Checa-Garcia et al.

\section{Title Page}

Abstract

Introduction

Conclusions

References

moderate (m)

heavy (h)

$2<R<5$

$\begin{array}{lll}4.7 & 2.3 & 0.23\end{array}$

13100

24100

$\begin{array}{lll}4.7 & 2.9 & 0.29\end{array}$

very heavy (vh)

$5<R<10 \quad 80100$

$\begin{array}{lll}5.2 & 3.9 & 0.39\end{array}$

extreme (e)

$\begin{array}{llll}332000 & 6.3 & 6.1 & 0.61\end{array}$

$\begin{array}{llll}426000 & 6.8 & 8.9 & 0.89\end{array}$

Tables

Figures

14

4

Back

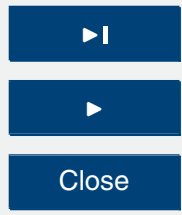

Full Screen / Esc

Printer-friendly Version

Interactive Discussion 
AMTD

7, 2339-2379, 2014

\section{Binning effects on in-situ raindrop size distribution measurements}

R. Checa-Garcia et al. used methods are shown. With regard to the methodology used to obtain the expressions, the generic method is introduced in the text. The moments used to calculate $\lambda$ are shown in parenthesis.

\begin{tabular}{lcccc}
\hline Method & Function $G$ & $\widehat{\mu}\left(G_{\text {exp }}\right)$ & $\widehat{\Lambda}(\widehat{\mu})$ & $\widehat{N}^{(g)}(\widehat{\Lambda}, \widehat{\mu})$ \\
\hline MM012(01) & $\frac{M_{1}^{2}}{M_{0} M_{2}}$ & $\frac{1}{1-G}-2$ & $(1+\mu) \frac{M_{0}}{M_{1}}$ & $M_{0} \frac{\Lambda^{(\mu+1)}}{\Gamma(\mu+1)}$ \\
MM246(24) & $\frac{M_{4}^{2}}{M_{2} M_{6}}$ & $\frac{7-11 G-\sqrt{14 G^{2}+G+1}}{2(G-1)}$ & $\sqrt{(3+\mu)(4+\mu) \frac{M_{2}}{M_{4}}}$ & $M_{2} \frac{\Lambda^{(2+\mu+1)}}{\Gamma(2+\mu+1)}$ \\
MM346(34) & $\frac{M_{4}^{3}}{M_{3}^{2} M_{6}}$ & $\frac{-8+11 G+\sqrt{G^{2}+8 G}}{2(1-G)}$ & $(4+\mu) \frac{M_{3}}{M_{4}}$ & $M_{3} \frac{\Lambda^{(3+\mu+1)}}{\Gamma(3+\mu+1)}$ \\
MM234(23) & $\frac{M_{3}^{2}}{M_{2} M_{4}}$ & $\frac{1}{1-G}-4$ & $(3+\mu) \frac{M_{2}}{M_{3}}$ & $M_{2} \frac{\Lambda^{(2+\mu+1)}}{\Gamma(2+\mu+1)}$ \\
MM456(45) & $\frac{M_{5}^{2}}{M_{4} M_{6}}$ & $\frac{1}{1-G}-6$ & $(5+\mu) \frac{M_{4}}{M_{5}}$ & $M_{4} \frac{\Lambda^{(4+\mu+1)}}{\Gamma(4+\mu+1)}$ \\
\hline
\end{tabular}

Title Page

Abstract

Introduction

Conclusions

References

Tables

Figures

14 DI

4

Back

lose

Full Screen / Esc

Printer-friendly Version

Interactive Discussion 
AMTD

7, 2339-2379, 2014

\section{Binning effects on in-situ raindrop size distribution measurements}

Table 3. Sampling area of analysed disdrometers. OSP has a second version with a smaller sampling area but the widely used features a sampling area of $100 \mathrm{~cm}^{2}$. POSS has a much larger sampling volume because it relies on a remote-sensing measurement method.

\begin{tabular}{lll}
\hline Disdrometer & Sampling Area & Measurement Method \\
\hline Parsivel OTT & $54 \mathrm{~cm}^{2}$ & Optical \\
2DVD & $100 \mathrm{~cm}^{2}$ & Optical (two beams) \\
Thies & $45.6 \mathrm{~cm}^{2}$ & Optical \\
JWD & $50 \mathrm{~cm}^{2}$ & Impact \\
OSP & $100 \mathrm{~cm}^{2}$ & Optical \\
POSS & $\gg 100 \mathrm{~cm}^{2}$ & Radar X-band \\
\hline
\end{tabular}

Title Page

Abstract

Introduction

Conclusions

References

Tables

Figures

14

$\Delta$

Back

Close

Full Screen / Esc

Printer-friendly Version

Interactive Discussion 
AMTD

7, 2339-2379, 2014

Binning effects on in-situ raindrop size distribution measurements

Table 4. Precipitation events from 2DVD data-set. Number of minutes with more than 100 drops after applying a typical filter for terminal velocities. Accumulated rainfall is measured in [mm] and maximum rainfall in $\left[\mathrm{mm} \mathrm{h}^{-1}\right]$.

\begin{tabular}{cccrrrrrr}
\hline Event & Min. & Date & $R_{\text {acc }}^{\text {2DVD }}$ & $R_{\max }^{2 \text { DVD }}$ & \multicolumn{1}{c}{$R_{\text {acc }}^{\text {OTT }}$} & $R_{\max }^{\text {OTT }}$ & $R_{\text {acc }}^{\text {OSP }}$ & \multicolumn{1}{c}{$R_{\max }^{\text {OSP }}$} \\
\hline A & 54 & 24 Apr 09:40 to 12:15 & 2.20 & 14.63 & 2.19 & 14.87 & 2.15 & 14.37 \\
B & 78 & 24 Apr 17:38 to 20:41 & 0.69 & 1.85 & 0.66 & 1.88 & 0.12 & 1.57 \\
C & 184 & 25 Apr 09:06 to 16:26 & 19.46 & 56.4 & 19.26 & 55.39 & 16.98 & 47.40 \\
D & 240 & 27 Apr 05:36 to 13:58 & 6.83 & 9.19 & 6.78 & 9.09 & 6.60 & 9.01 \\
E & 109 & 01 May 16:05 to 20:28 & 3.14 & 8.73 & 3.10 & 8.67 & 2.90 & 8.54 \\
F & 220 & 11 May 18:08 to 23:01 & 7.13 & 11.97 & 7.04 & 11.95 & 6.89 & 11.26 \\
All & 885 & - & 39.45 & 56.4 & 39.04 & 55.39 & 35.64 & 47.40 \\
\hline
\end{tabular}

Title Page

Abstract

Introduction

Conclusions

References

Tables

Figures

14

$\Delta$

4

Back

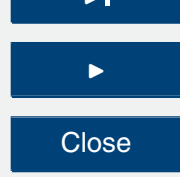

Full Screen / Esc

Printer-friendly Version

Interactive Discussion 


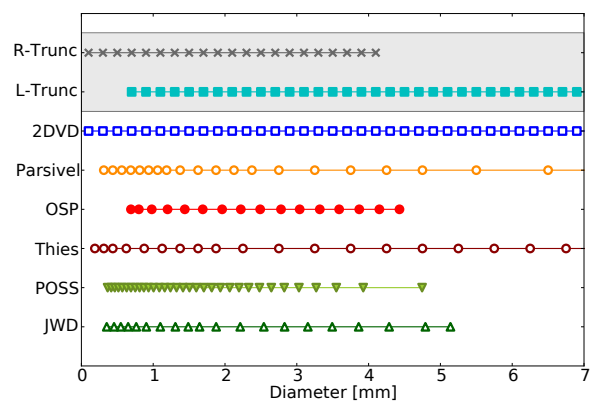

AMTD

7, 2339-2379, 2014

\section{Binning effects on in-situ raindrop size distribution measurements}

\section{R. Checa-Garcia et al.}

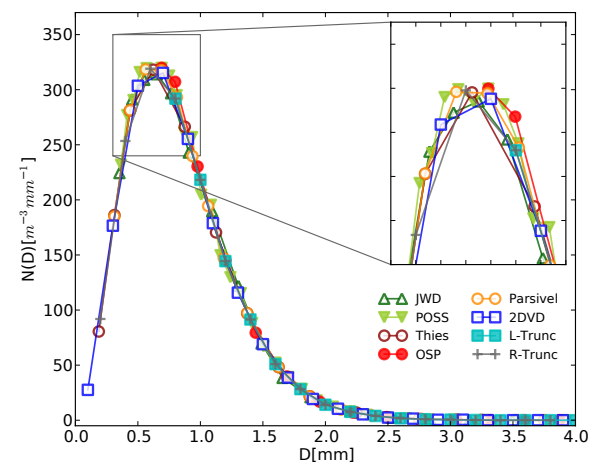

Title Page

Abstract Introduction

Conclusions

References

Tables Figures

Fig. 1. Top panel: Bins analysed in this study showing the central size classification values used by each instrument, as extracted from Campos and Zawadzki (2000); Sheppard and Joe (1994); Loffler-Mang and Joss (2000). The information of Thies and Parsivel OTT disdrometers were provided by the manufacturer. In the case of Parsivel OTT the first and second bins were eliminated as the instrument does not record information on these bins. Bottom panel: The composite DSD resulting from the generation of 200 samples is shown for the category of moderate rainfall intensity. The relevance of the binning process is observed, even in smaller drops where the density of bins is greater.

Printer-friendly Version

Interactive Discussion

14

4

Back

Close

\section{Full Screen / Esc}

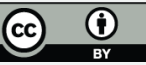



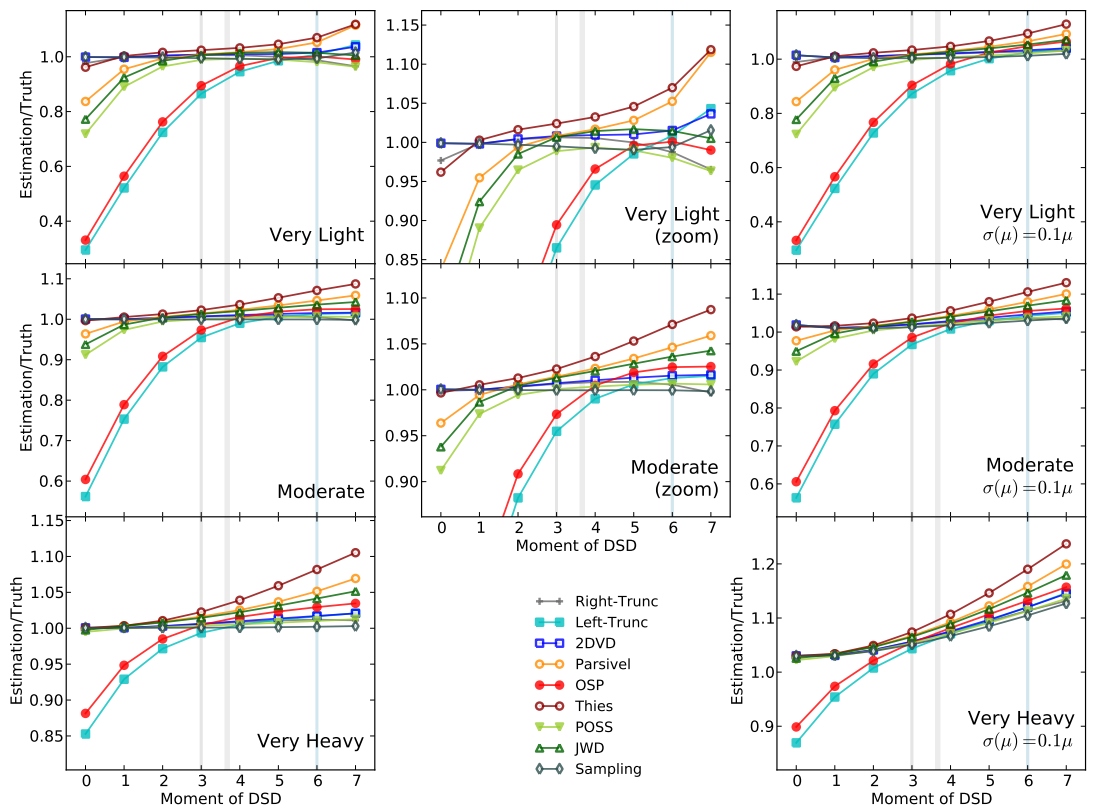

AMTD

7, 2339-2379, 2014

Binning effects on in-situ raindrop size distribution measurements

R. Checa-Garcia et al.

Fig. 2. The first column reports the estimates for each of the DSD moments ranging from 0 to 7 for three precipitation categories (very light, moderate and very heavy) based on 5000 samples. The second column shows the differences in the higher-order moments. The third column shows the results when a Gaussian noise is introduced in the $\mu$ variable for each sample. The true value is obtained from the given analytical values $\mu, \lambda$ and $N^{(g)}$ and the expression (2). The sampling case is based on the sample moment estimates without carrying out a classification into bins. In the third column, the sampling represents the effective combination of the sampling case and the uncertainty in the moment estimates due to the Gaussian noise introduced in $\mu$. To illustrate the relationship with integral rainfall parameters the three vertical lines represent, from left to right, the position of the LWC $\left(=C_{\mathrm{LWC}} M_{3}\right), R\left(\simeq C_{R} M_{3.67}\right)$ and $Z\left(=M_{6}\right)$, where the constants $C_{\mathrm{LWC}}$ and $C_{R}$ allow for the retrieval of the usual units, which are presented in Ulbrich (1983).

Title Page

Abstract Introduction

Conclusions

References

Tables

Figures

14

$\rightarrow 1$

4

Back

Close

Printer-friendly Version

Interactive Discussion 


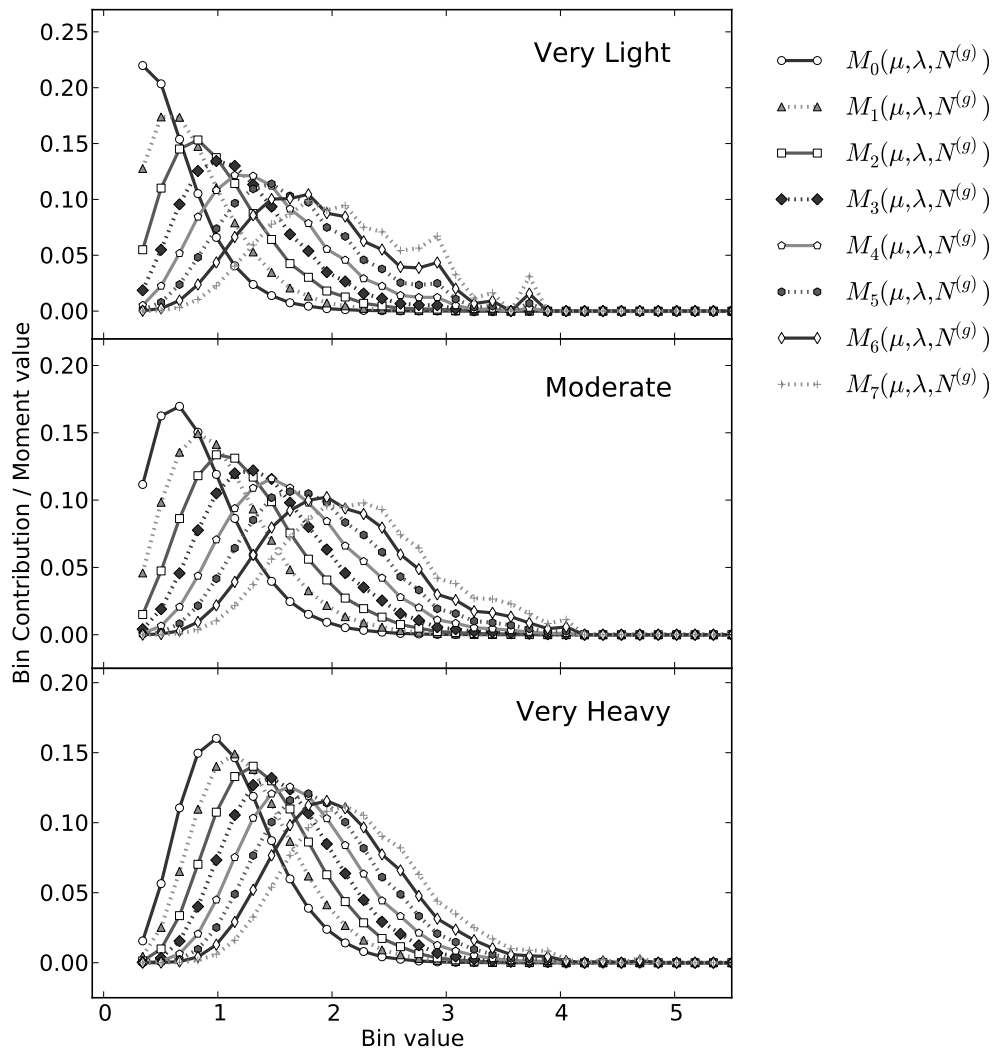

AMTD

7, 2339-2379, 2014

Binning effects on in-situ raindrop size distribution measurements

R. Checa-Garcia et al.

Title Page

Abstract

Introduction

Conclusions

References

Tables

Figures

14

$\Delta$

4

Back

Close

Full Screen / Esc

Fig. 3. The relative contribution of each bin to the value of each moment was determined for each category and for the uniform bins similar to those of the 2DVD disdrometer. The curves are progressively displaced to greater diameters and approach functions that can be modeled by means of Gaussian distributions. This modeling allows for the interpretation of Fig. 2. These results are based on the simulation of 1000 samples for each category. 


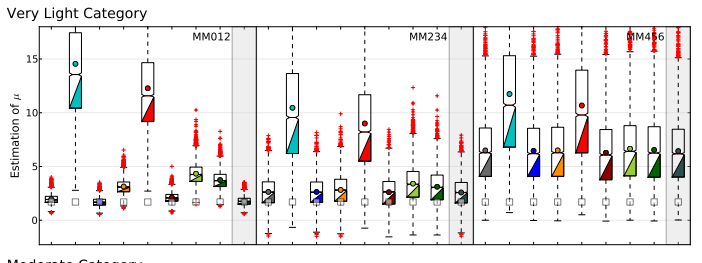

AMTD

7, 2339-2379, 2014

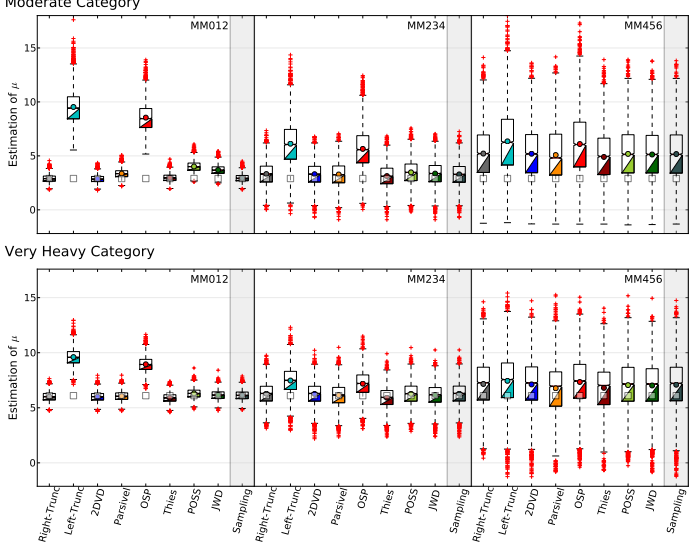

\section{Binning effects on in-situ raindrop size distribution measurements}

R. Checa-Garcia et al.

\section{Title Page}

Fig. 4. The estimates of $\mu$ are compared for three different categories by three moment methods. The results are shown for the entire group of binnings analysed with experimental distributions of the estimated $\mu$ and the corresponding box-plot diagrams. The central line in the box-plot represents the median, while the two inferior and superior lines that define the box represent the first $\left(Q_{1}\right)$ and third $\left(Q_{3}\right)$ quartiles. The lines that define the box-plot extend to 1.5 times the value of $I Q R=Q_{3}-Q_{1}$, which is further than the first and third quartiles. If the values are not within this range, they are considered outliers. The empty squares represent the actual values (reported in Table 1); the circles represent the average values of the distributions. The outliers are represented as red addition symbols. The box-plots are based on 5000 samples. From left to right each column reports the results obtained with the moment methods MM012, MM234 and MM456.

14

4

\section{Full Screen / Esc}

Printer-friendly Version

Interactive Discussion

\section{Close}




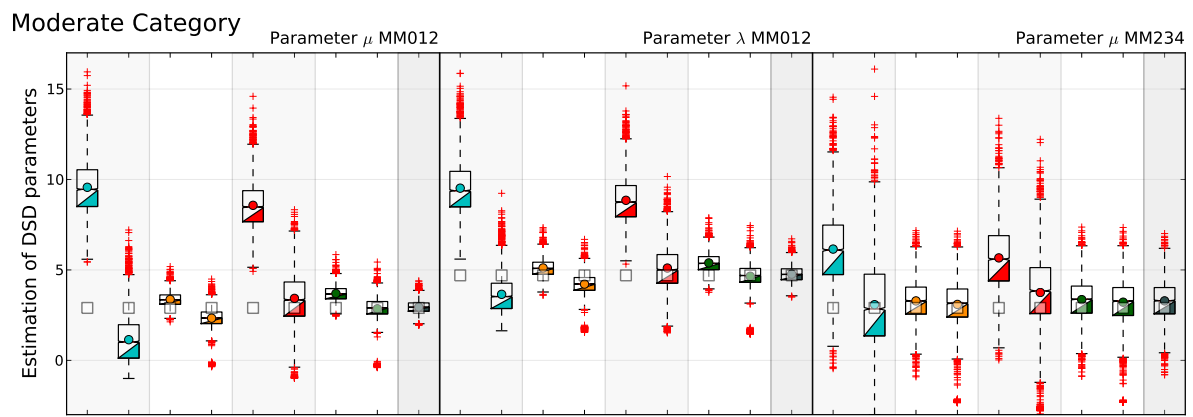

AMTD

7, 2339-2379, 2014

Binning effects on in-situ raindrop size distribution measurements

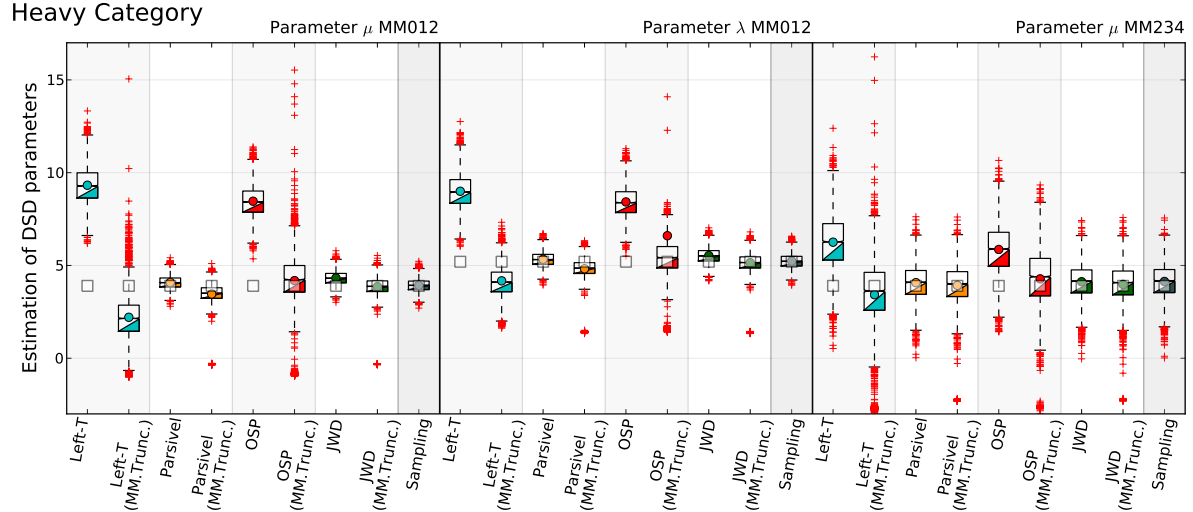

Fig. 5. The gamma distribution estimates are compared using the moment and truncated moment methods (referred as MM.Trunc) for two different categories and for a subset of disdrometers analysed that are more sensitive to small drops. The experimental distributions of the estimated $\mu$ and $\lambda$ parameters were constructed as box-plot type diagrams. The empty squares represent the real values, and the circles represent the average values of the samples. The line that divides the box-plot is the median, and the boxplot shows different quartiles. Compare the presence of outliers in this Figure with those shown in Fig. 4. The box-plots are based on 5000 samples.
Title Page

Abstract

Introduction

Conclusions

References

Tables

Figures

14

$>1$

4

Back

Close

\section{Full Screen / Esc}

Printer-friendly Version

Interactive Discussion 


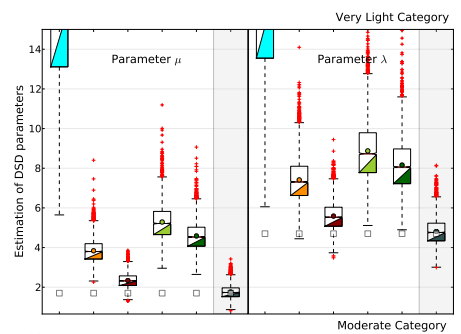

AMTD

7, 2339-2379, 2014

Binning effects on in-situ raindrop size distribution

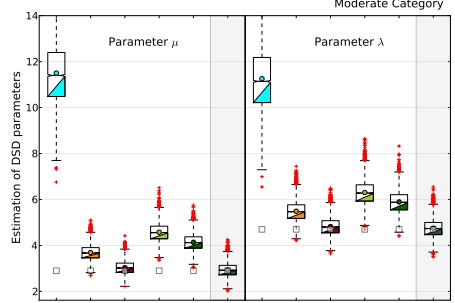
measurements

R. Checa-Garcia et al.

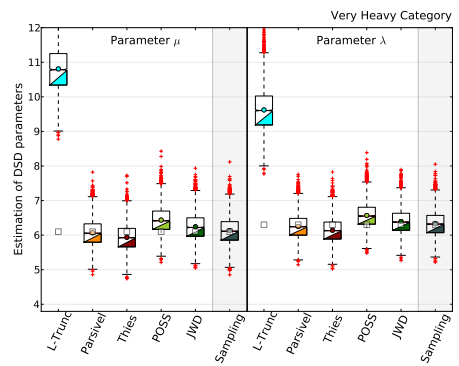

Title Page

Abstract

Introduction

Conclusions

References

Tables

Figures

Fig. 6. The predictions are compared by means of the MLE method for several binning methods. The Left-Truncated and OSP provide results similar to those of MM012, thus the OSP is omitted in this figure. Additionally, the Left-Truncated is not entirely visualised to allow for a better visualisation of the detailed differences between the disdrometers shown here. Similarly, the 2DVD case is located between that of the Thies device and sampling, and it is omitted. The box-plots are based on 5000 samples.

14

4

$>$

\section{Full Screen / Esc}

Printer-friendly Version

Interactive Discussion 

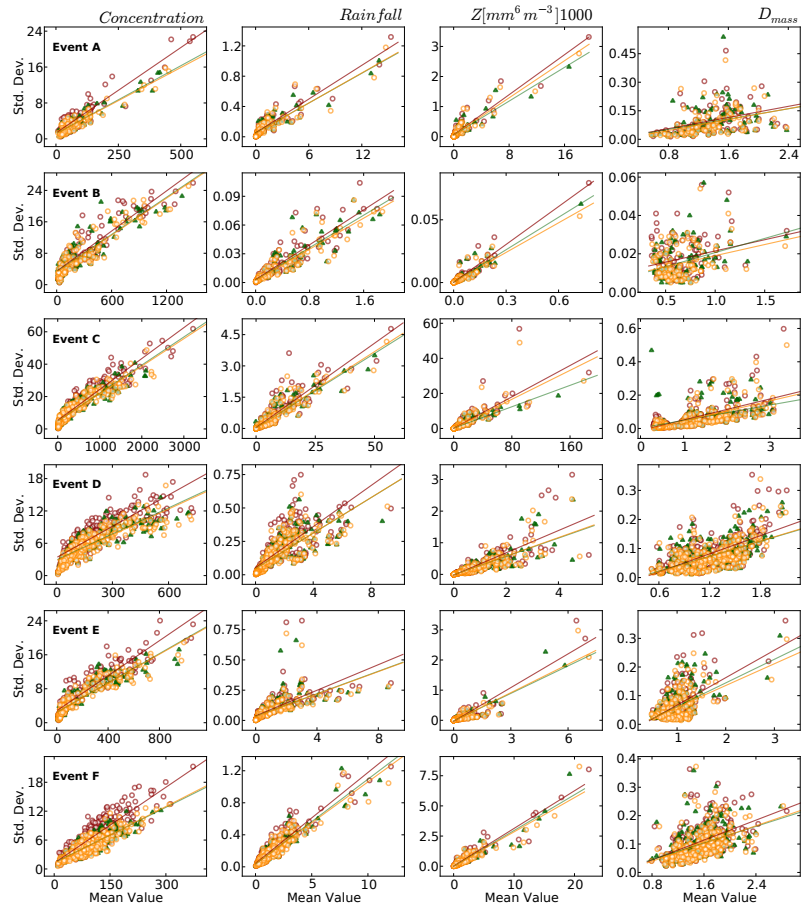

$\therefore$ Thies

Fig. 7. Estimation of standard deviation of each DSD moment estimator by a re-sampling technique. For each experimental DSD, the standard deviation over the built sub-samples is calculated. Then, the value of standard deviation is interpreted as an estimator of the sampling error of the mean value. The meanings of colours are the same as those in Fig. 1. The values of reflectivity are scaled by a factor 1000 . Linear regressions were included to indicate the general increasing tendency in the estimation of sampling error with the mean value. Each point represents the experimental DSD over a time resolution of $1 \mathrm{~min}$ with at least 20 drops.

AMTD

$7,2339-2379,2014$

Binning effects on in-situ raindrop size distribution measurements

R. Checa-Garcia et al.

Title Page

Abstract

Introduction

Conclusions

References

Tables

Figures

14

$\rightarrow 1$

4

Back

Close

\section{Full Screen / Esc}

Printer-friendly Version

Interactive Discussion 

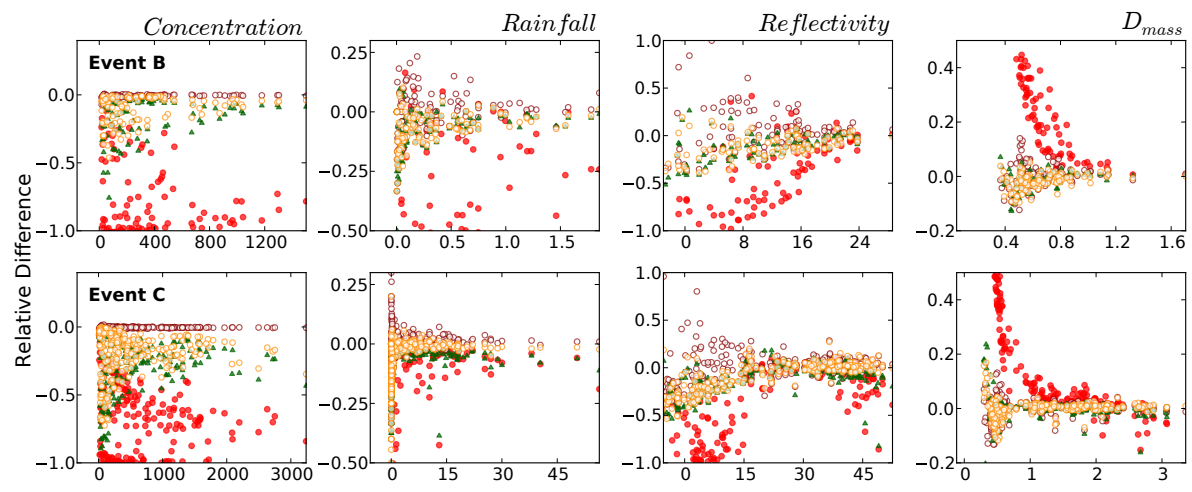

(2DVD) $N_{t}\left[m^{-3}\right]$

(2DVD) $R[m m \triangleleft h]$

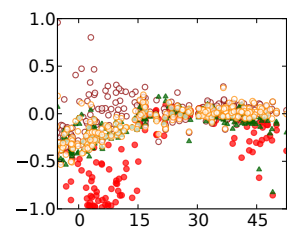

(2DVD) $10 \log _{10}(Z)$

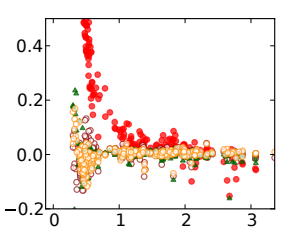

(2DVD) $D_{m a s}[m m]$

$\circ \circ$ Thies $\quad \circ$ Parsivel $\triangle \triangle$ JWD $\therefore$ OSP (Optical SpectroPluviometer)

Fig. 8. Relative difference $\left(\bar{X}_{D}-X_{2 \mathrm{DVD}}\right) / X_{2 \mathrm{DVD}}$ where the disdrometer $D$ was successively OSP, Thies, Parsivel OTT and JWD, and $X$ is an integral rainfall parameter. The difference is calculated between the estimation of mean values for each disdrometer by a re-sampling technique and the original value of the 2DVD disdrometer. The meanings of the colours are the same as those in Fig. 1. Each point represents the experimental DSD over a time resolution of $1 \mathrm{~min}$ with at least 100 drops. Events $B$ and $C$ were the events with the fewest and greatest values of total accumulated rainfall, respectively.

\section{Binning effects on in-situ raindrop size distribution measurements}

R. Checa-Garcia et al.

\section{Title Page}

4

\section{Full Screen / Esc}

Printer-friendly Version

Interactive Discussion 


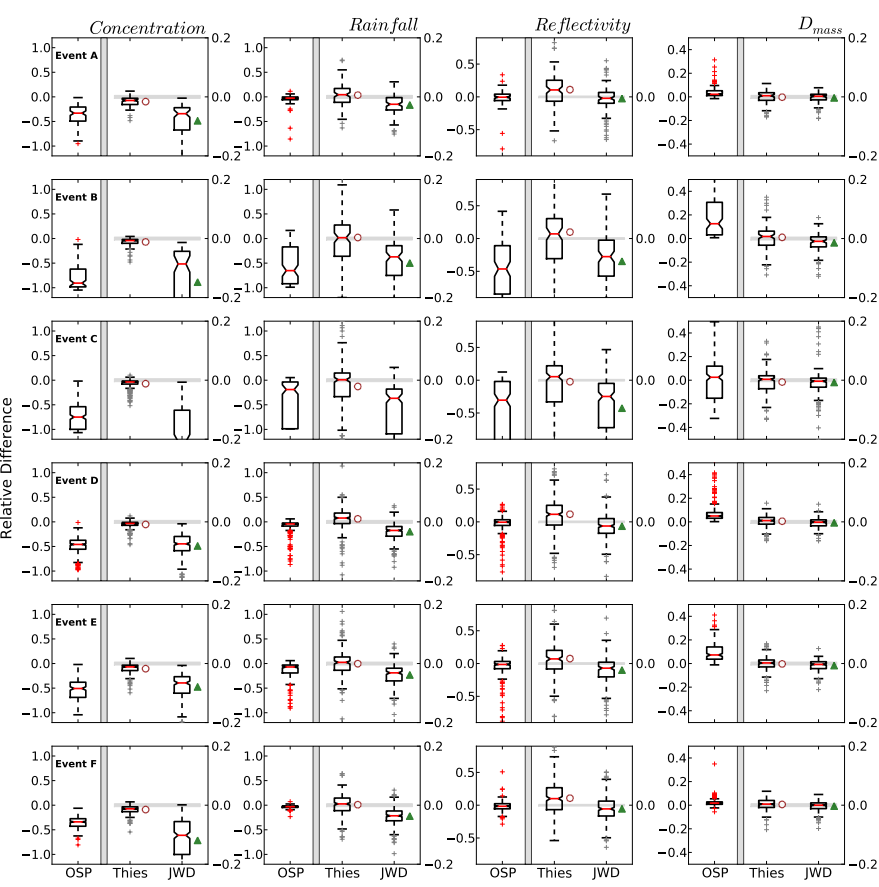

Fig. 9. Box-plots of the relative difference $\left(\bar{X}_{D}-X_{2 \mathrm{DVD}}\right) / X_{2 \mathrm{DVD}}$ where the disdrometer $D$ was successively OSP, Thies and JWD, and $X$ is an integral rainfall parameter. The difference is between the estimation of the mean values for each disdrometer, as determined by a re-sampling technique, and the original value of the 2DVD disdrometer. The meanings of colours are the same as those in Fig. 1. The box-plots are calculated from the experimental DSD over a time resolution of $1 \mathrm{~min}$ with at least 100 drops. The adjacent symbols are the mean values of the relative difference for each event. The results for the Parsivel OTT were intermediate between those of the Thies and JWD disdrometers. The $y$ axis scale for OSP instrument is 5 times larger than for Thies and JWD.
AMTD

7, 2339-2379, 2014

Binning effects on in-situ raindrop size distribution measurements

R. Checa-Garcia et al.

Title Page

Abstract Introduction

Conclusions

References

Tables

Figures

14

$>1$

4

Back

Close

Printer-friendly Version

Interactive Discussion 